\title{
Improvement of biochemical methods of polyP quantification
}

\author{
Samuel Bru ${ }^{1}$, Javier Jiménez ${ }^{1}$, David Canadell ${ }^{2, \#}$, Joaquín Ariño ${ }^{2, *}$, Josep Clotet $^{1, *}$ \\ ${ }^{1}$ Department of Basic Sciences, Faculty of Medicine and Health Sciences. Universitat Internacional de Catalunya. Barcelona, Spain. \\ ${ }^{2}$ Departament de Bioquímica i Biologia Molecular and Institut de Biotecnologia i Biomedicina, Universitat Autònoma de Barcelona. \\ Cerdanyola del Vallès, Spain. \\ \# Present Address: Cell Signaling Research Group, Departament de Ciències Experimentals i de la Salut, Universitat Pompeu Fabra, \\ Barcelona, Spain. \\ * Corresponding Author: \\ J. Ariño, Tel: +34 935812182; E-mail: joaquin.arino@uab.cat \\ J. Clotet, Tel: +34 935042015; E-mail: jclotet@uic.cat
}

\begin{abstract}
Polyphosphate (polyP) is an abundant and physiologically important biomolecule for virtually any living cell. Therefore, determination of changes in cellular content of polyP is crucial for its functional characterization. Determination of cellular polyP has been performed by many different methods, and the lack of a standardized procedure is possibly responsible for the large dispersion of results found in the relevant literature. For a relatively simple organism, such as the yeast Saccharomyces cerevisiae, this variation can be up to 12-fold. polyP extraction and determination of free phosphate released by enzymatic degradation of the polymer is a method quite common and relatively straightforward for polyP determination. By using the yeast $S$. cerevisiae as model, we have experimentally evaluated the different steps in this procedure in order to identify critical issues that might explain the disparate reported results. As the main output of this evaluation we propose a straightforward and robust procedure that can be used as gold standard protocol for cellular polyP purification and determination from unicellular organisms, thus providing consistency to measurements and facilitating interlaboratory comparisons and biological interpretation of the results.
\end{abstract}

doi: 10.15698/mic2017.01.551

Received originally: 29.07.2016;

in revised form: 24.10.2016,

Accepted 28.10.2016,

Published 29.12.2016.

Keywords: polyphosphate, yeast, Saccharomyces cerevisiae, neutralphenol.

\section{Abbreviations:}

DAPI - 4',6-diamidino-2-phenylindole, polyP - polyphosphate.

\section{INTRODUCTION}

Inorganic polyphosphate (polyP) is a linear polymer of orthophosphate with many biological functions in both prokaryotic and eukaryotic organisms. In microorganisms, polyP plays an important function as stores of phosphorus and energy, in cation homeostasis, and in adaptation to stress conditions [1]. Very recently, a role for polyP in posttranslational modification of Lys residues in proteins has been reported [2]. In complex organisms, as humans, this polymer is involved in many diverse functions such as blood coagulation, bone formation, immune response, regulation of calcium level in mitochondria, or neurotransmission (see [3] and references herein). In addition, polyP is used in diverse industrial processes, including water treatment, and as fertilizer in agriculture [4]. Therefore, research on polyP is of great relevance in a variety of fields, ranging from the environmental to the biological sciences.

In the past, quantification of intracellular polyP content has been carried out by means of a diversity of approaches and methodologies, often yielding results that are difficult to compare. One of the most commonly employed methods to quantify polyP has been ${ }^{31} \mathrm{P}$ NMR [5-7]. While this technique has produced a foundational knowledge in the field of polyP research, it suffers of significant drawbacks. For instance, ${ }^{31} \mathrm{P}$ NMR only detects phosphorus-containing molecules on the basis of bond class. Therefore, the method is not ideally suited to distinguish between polyP and molecules that also can contain phosphoanhydride bonds, such as nucleotides. Moreover, the abundant presence of P-ester compounds can obscure the comparatively smaller polyP signal in the majority of biological samples. In addition, usually NMR equipment is not well suited for timeresolved experiments in which environmental conditions must be quickly changed.

Staining with relatively specific dyes has been widely used for monitoring polyP accumulation both in vivo and in vitro. An example is the utilization of the metachromatic interaction of polyP with toluidine blue [8], although the 
most widely used method is based on the interaction between polyP and the fluorochrome 4',6-diamidino-2phenylindole (DAPI). DAPI is usually used for DNA detection, because blue fluorescence is apparent when the stained cells are viewed under UV light. However, the binding of DAPI to polyP also shifts the peak of DAPI and the fluorescence intensity at this shifted wavelength is proportional to the concentration of polyP $[9,10]$. Although previous studies concluded that the presence of DNA do not complicate the fluorimetric quantification of polyP with DAPI, it has recently been described that RNA, inositol phosphates, amorphous calcium phosphates and nucleotides can cause significant interference at the wavelengths used to measure polyP, concluding that the DAPI-polyP interaction is sensitive to sample composition [7, 11-14] and can lead to high variation between samples. Recently a new method for measuring polyP based on spectromicroscopy (Raman microscopy) has been developed [13, 15]. Raman microscopy is a fast evolving technology, but currently its sensitivity is relatively low and requires equipment not widely available.

Protocols that determine polyP concentration biochemically offer an appealing alternative to the methods discussed above, as exemplified by the early determination of polyP levels in different mammalian cells and tissues performed by the Kornberg's laboratory [16]. Such enzymatic

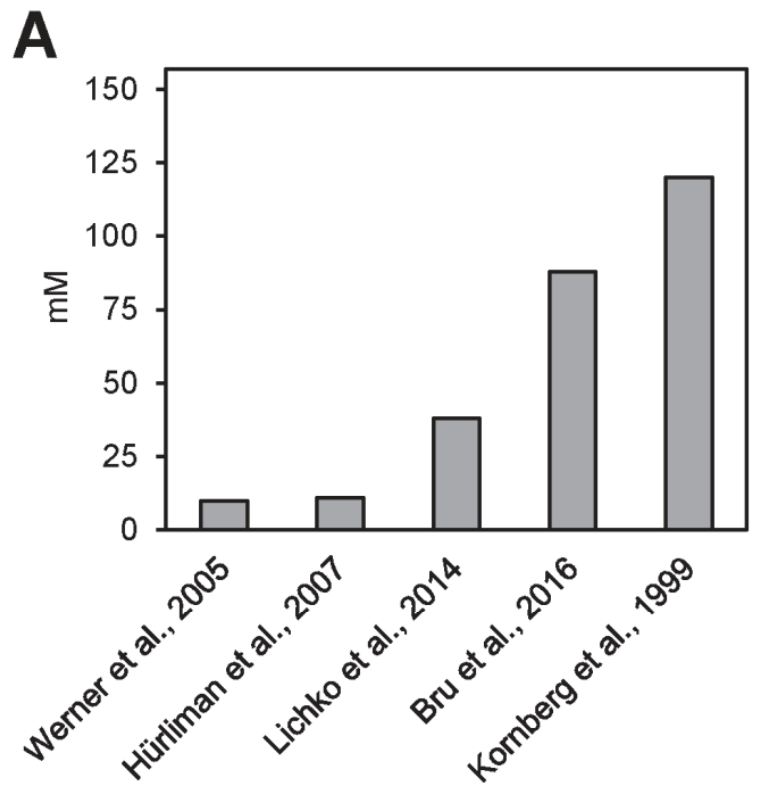

Extraction
(Figure 2) $\left\{\begin{array}{l}\text { Phenol pH= } \\ \text { Phenol pH= 4.3 } \\ \mathrm{H}_{2} \mathrm{SO}_{4} \\ \mathrm{HClO}_{4}\end{array}\right.$ Purification
(Figure 3) $\left\{\begin{array}{ll}\text { Affinity column } & \text { Quantification } \\ \text { Ethanol precipitation } & \text { (Figure 4 and S2) }\end{array}\left\{\begin{array}{l}\mathrm{Ppx} \rightarrow \text { malachite green } \\ \mathrm{DAPI}\end{array}\right.\right.$ and quantification. methods are based on the use of polyP kinase, followed by ATP measurement $[17,18]$, or that of exopolyphosphatase followed by determination of free orthophosphate [19-21], and have been used in a variety of cells, from microorganisms to mammalian tissues. These methods are widely used because of their high sensitivity (particularly if radioactive phosphate is used), but they are not devoid of problems. For instance, they generally require of purification procedures, which can lead to erratic and/or low yields and, currently, no commercial sources exist for the required enzymes. In addition, even for enzyme-based protocols, the disparity of procedures used for purification and assays complicates inter-laboratory comparisons.

Possibly, the lack of a truly validated method to quantify cellular polyP content has been a drawback that has hampered the advance in the field. In fact, after evaluation of the relevant literature concerning the budding yeast Saccharomyces cerevisiae, we noticed a large disparity in the polyP content reported for this yeast that was difficult to explain on the basis of different genetic backgrounds or growth conditions. We considered that, at least in part, such inconsistency could derive from the use of different methods for polyP determination. In this work we analyze and compare possible alternatives for the main steps of exopolyphosphatase-based methods for polyP quantification, discuss the relative advantages, and propose a unified

FIGURE 1: High variability on polyP determination in S. cerevisiae. (A) poly $\mathrm{P}$ content in $\mathrm{mM}$ concentration according to different authors. Values were converted to $\mathrm{mM}$ according to the following assumptions: i) The volume of the haploid cell is $42 \mathrm{fl}$, ii) One $O_{660}$ unit equals to $2.6 \times 10^{7}$ cells and represents $50 \mu \mathrm{g}$ of RNA. The $\mathrm{Mw}$ for the $\left[-\mathrm{PO}_{3}^{-}{ }^{-}\right]$monomer is $79 \mathrm{~g} / \mathrm{mol}$. (B) Flow chart of this work, showing the different possibilities explored in each of the three parts needed for determining polyPs: extraction, purification 
protocol for polyP determination that will help in the advance of the research of this polymer.

\section{RESULTS AND DISCUSSION}

Large discrepancies in determination of polyP cellular content claim for standardized determination methods

A major issue when any cellular metabolite from a given source is determined is to evaluate whether the values obtained are congruent with those previously reported under similar circumstances (growth conditions, genetic background, etc.) in the literature. In the case of polyP content in yeast cells, this is a difficult task because, in many cases, the units employed are different (i.e. $\mu \mathrm{g} / \mathrm{OD}$ unit, $\mu \mathrm{mol} / \mathrm{mg}$ RNA, $\mathrm{nmol} \mathrm{Pi} / 10^{\mathrm{n}}$ cells, and so on). We have made an attempt to integrate data from the literature in a common frame of measurement units $(\mathrm{mM} \mathrm{Pi})$. The result of this transformation applied to five independent reports [22-26] is shown in Figure 1. As it can be seen, there are large differences (up to 12-fold) in the amount of cellular polyP determined. It might be argued that this disparity could result from the use of different genetic backgrounds in the experiments. However, in several of the examples included in Figure 1, the BY4741 strain, or very close derivatives, were employed. The use of different backgrounds, even if it can result in some fluctuations, can hardly explain the large variations observed (our own unpublished data, see also reference [25]). In addition, the Pi content in the media used and the growth phase of the cultures were fairly consistent among the different experiments. Therefore, it is reasonable to conclude that a substantial component of such variations must reside in the use of different protocols for polyP extraction, purification and quantification. In consequence, we considered necessary to carry out a comparative analysis of different options than can be proposed for each of these steps (Figure 1B).

\section{Influence of the extraction method on polyP quantifica- tion}

There is plenty of evidence that polyP polymers are labile to acidic conditions [27]. In fact, acid treatment at high temperature has been used for polyP quantification upon hydrolysis of the polymer [28]. However, some methods for polyP extraction from cells or tissues involve the use of strong acids (usually sulfuric or perchloric). Therefore, we considered the possibility that this step might influence in the recovery of polyP from its original source. To evaluate this, we incubated $4 \mu \mathrm{g}$ of commercial polyP for different periods of time with the reagents more frequently used in the literature: a phenol-based extraction solution at $\mathrm{pH} 8.0$ (Figure 2A), the same solution at pH 4.8 (Figure 2B), $1 \mathrm{M}$ sulfuric acid (Figure 2C) or $1 \mathrm{M}$ perchloric acid (Figure 2D). As it can be observed, treatment with strong acids results
A

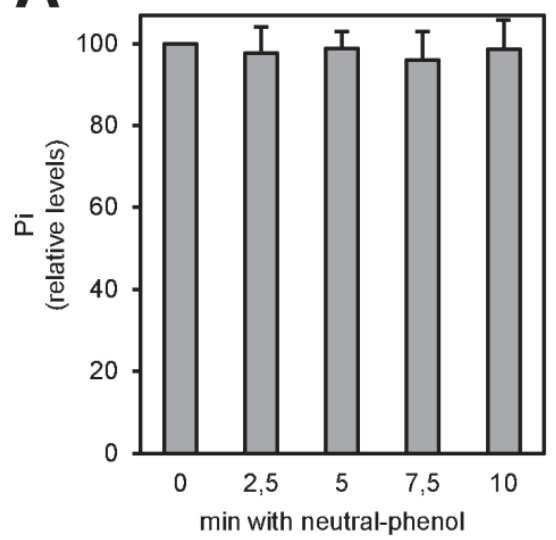

C

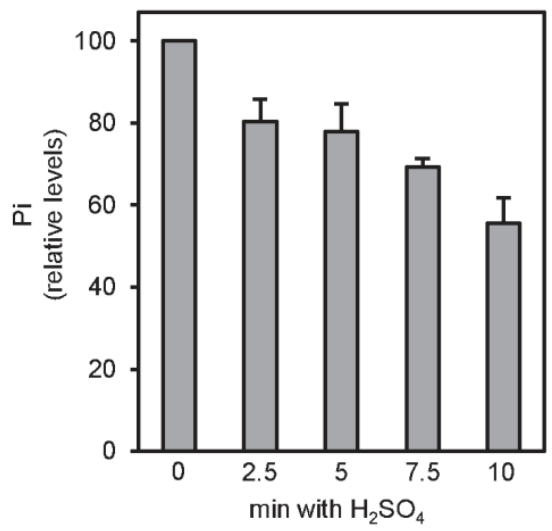

B

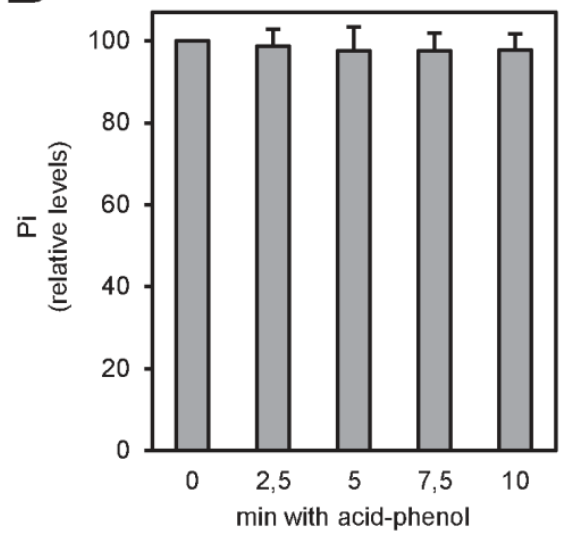

D

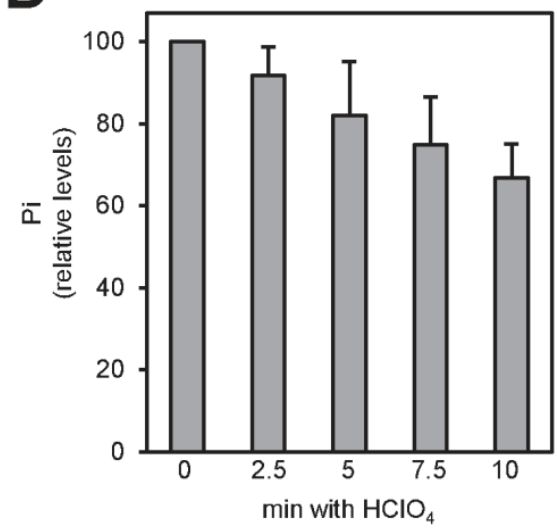

FIGURE 2: polyP is unstable when strong acids are employed during the extraction process. Relative amount of polyP after treatment with the different extraction solutions. Commercial polyP $(4 \mu \mathrm{g})$ was incubated at different times with the different extraction solutions: (A) neutral-phenol at $4^{\circ} \mathrm{C}$, (B) acid-phenol at $4^{\circ} \mathrm{C}$, (C) $1 \mathrm{M} \mathrm{H}_{2} \mathrm{SO}_{4}$ at room temperature and (D) $1 \mathrm{M}$ $\mathrm{HClO}_{4}$ at $4^{\circ} \mathrm{C}$. The mixes were neutralized, purified using affinity columns and the polyP eluted with MilliQ water. polyP amount was determined from the amount of Pi produced upon treatment with $\mathrm{rPpx} 1$. The graphs represent the percentage of polyP relative to time zero of each condition. Mean \pm SEM from 3 independent experiments is shown. 
in a time-dependent decrease in the amount of measured polyP, which was reduced up to one half of the untreated aliquot in as little as $10 \mathrm{~min}$. This implies that some commonly used extraction methods would result in polyP degradation at this step, with the consequent impact in the final quantification.

\section{The purification method strongly influences the size and amount of recovered polyP}

Two of the most frequently used methods for polyP purification upon extraction are affinity chromatography (usually silica-based) and ethanol precipitation. Reported evidence indicated that different extraction methods may result in size fractionation of recovered polyP [29]. To test possible purification method-dependent differences in the length and recovery of polyP, we extracted polyP from two aliquots of yeast cultures by the phenol/chloroform $(\mathrm{pH}$ 8.0) method and samples were purified either by ethanol precipitation or by column chromatography (see Materials and Methods). Aliquots of the ethanol-precipitated material, as well as of the flow-through and the eluate of the chromatography were analyzed by polyacrylamide electrophoresis. As shown in Figure 3A, the chromatography step results in a dramatic size-dependent fractionation: polyP chains shorter than $60-80$ residues were not retained by the column and appeared in the flow-through (which is usually discarded). This fractionation by size drastically decreased polyP recovery in the eluate which, upon quantification by degradation with rPpx1 and determination of the released phosphate, was estimated to be around 30$40 \%$ of the initial amount of polymer measured after the ethanol precipitation method (Figure 3B). Therefore, while extraction of polyP with the neutral phenol/chloroform method does not appear to introduce significant size selection bias (compare Figure $3 \mathrm{~A}$ in this work with Figure 3 in reference [29]), subsequent column purification results in size fractionation leading to significant underestimation of the amount of cellular polyP.

Finally, we examined different factors that might affect the recovery in the process of precipitating polyP with ethanol. To this end, we added to the mixture various monovalent cations, magnesium or glycogen (as carrier). As deduced from Figure $3 C$, none of these components had significant effect on the recovery of polyP.

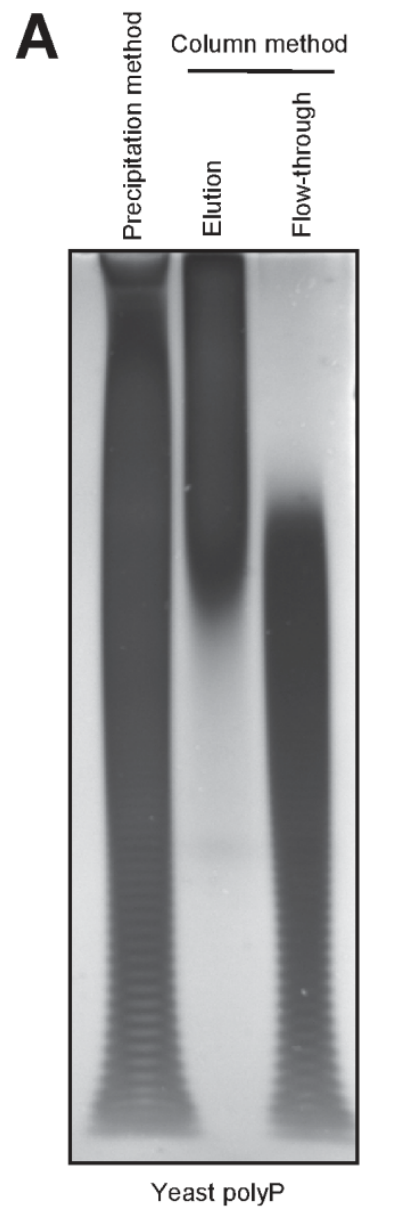

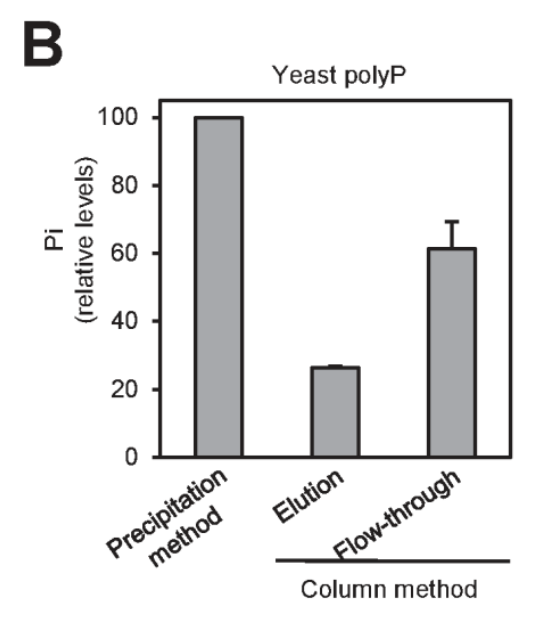

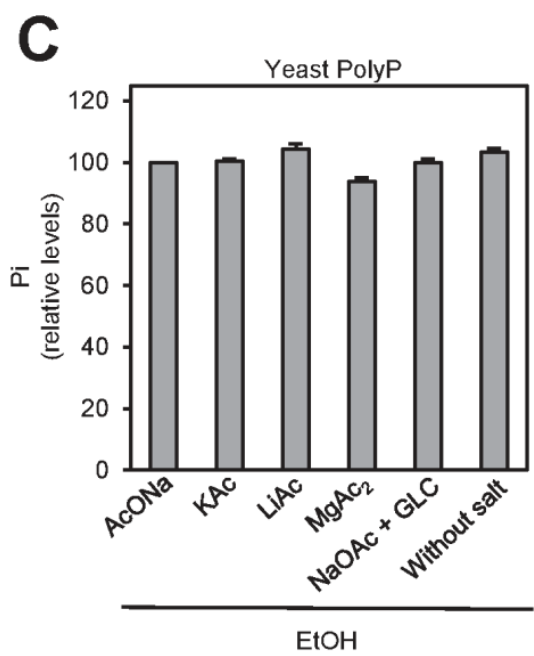

FIGURE 3: Ethanol precipitation method yields a broader spectrum of polyP sizes than affinity column purification. (A) PAGE and DAPI staining of polyP differently purified. polyP was extracted using the neutral phenol/chloroform procedure from a yeast pellet equivalent to $10^{7}$ logarithmically growing yeast cells. The aqueous phase was treated with DNAse and RNAse solution, and purified by affinity columns or by ethanol precipitation. The resulting polyP fractions: precipitated (in the case of the ethanol) and eluted and flow-through (in the case of the affinity column) were analyzed by PAGE followed by DAPI staining. (B) Percentage of polyP relative to the purification method. polyP amount was determined using the same fractions obtained in panel A. The graph represents the Mean \pm SEM from 3 independent experiments. (C) Relative amount of polyP obtained after the precipitation of polyP in the presence of different monovalent salts, divalent salts and a carrier. Aqueous phase from panel A was used. The graph represents the percentage of polyP relative to precipitation with NaOAc. Mean \pm SEM from 3 independent experiments is shown. GLC, glycogen. 


\section{Characterizing the conditions for recombinant Ppx1-based polyP determinations}

As described above, degradation of polyP by the exopolyphosphatase activity of yeast Ppx1 followed by measuring released phosphate is a common method for polyP determination. Therefore, it was considered of interest to test a number of practical aspects of this reaction suitable to be optimized. Ppx1 purified from yeast was reported to be fairly active up to $47^{\circ} \mathrm{C}$ [20], so we first examined the possibility to reduce the period of digestion with the enzyme by raising the incubation temperature. As shown in Figure $\mathrm{S} 1 \mathrm{~A}$, the enzyme was highly active at $60^{\circ} \mathrm{C}$ but only for a relatively short period of time ( $20 \mathrm{~min})$, followed by a sudden decline in activity, likely due to a thermal inactivation process (Figure S1B). In contrast, when incubated at $37^{\circ} \mathrm{C}$, rPpx1 showed lesser, but constant activity during the ex- periment $(60 \mathrm{~min})$. As a result, incubation at $37^{\circ} \mathrm{C}$ resulted in a more exhaustive digestion of the polyP. However, since usually the amount of polyP to be measured is far smaller than the four $\mu \mathrm{g}$ used in this assay, it could be feasible to shorten the incubation time (and thus the duration of the assay) by raising the incubation temperature. We also tested the range of $\mathrm{pH}$ suitable for the use of the recombinant Ppx1 (Figure S1C). As observed, the enzyme was highly active in the $\mathrm{pH}$ range of 5.5 to 8.5 , which fits well with the range reported for the native enzyme [20].

We observed that equivalents amounts of polyP either obtained by synthesis or purified from yeast (by neutralphenol extraction followed by ethanol precipitation) displayed different degradation kinetics, being slower that of the polymer extracted from yeast (Figure 4A). Because certain charged molecules, such as heparin $[30,31]$ or
A
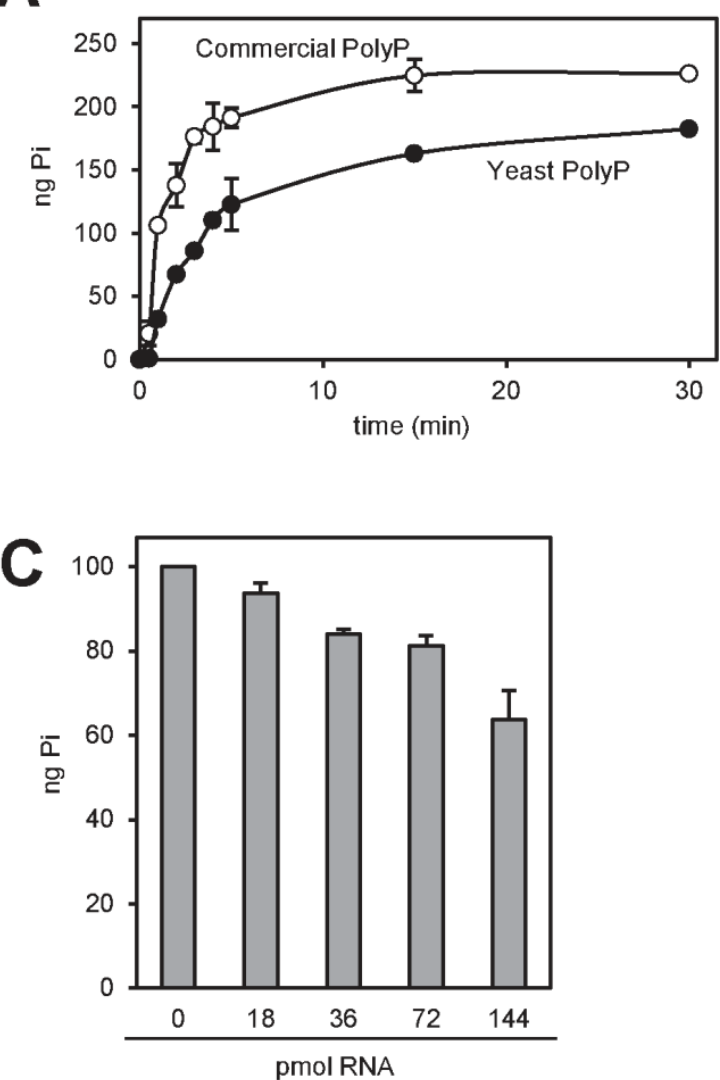

B

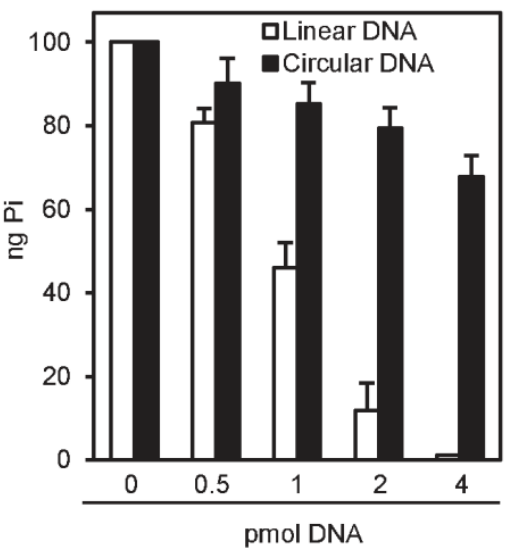

D

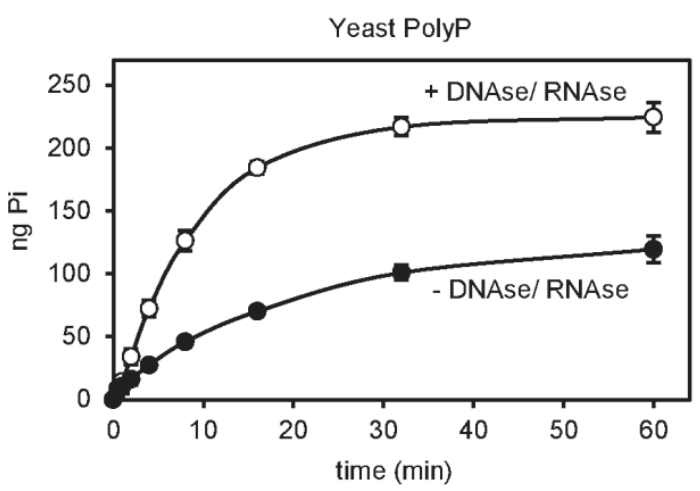

FIGURE 4: rPpx1 activity is inhibited by the presence of DNA and RNA. (A) Kinetic of the rPpx1 polyP digestion. rPpx1 (10 ng) was incubated with $250 \mathrm{ng}$ of commercial polyP or yeast polyP, in $20 \mathrm{mM}$ Tris- $\mathrm{HCl} \mathrm{pH} 7.50$ containing $5 \mathrm{mM}$ magnesium acetate and $100 \mathrm{mM}$ ammonium acetate at $37^{\circ} \mathrm{C}$. Samples were taken at the indicated times to quantify the released Pi. Mean $\pm \mathrm{SEM}$ from 3 independent experiments is shown. (B) rPpx1 activity on polyP in the presence of increasing amount of DNA. rPpx1 (10 ng) was incubated with $100 \mathrm{ng}$ of commercial polyP in $20 \mathrm{mM}$ Tris- $\mathrm{HCl} \mathrm{pH} 7.50$ containing $5 \mathrm{mM}$ magnesium acetate and $100 \mathrm{mM}$ ammonium acetate and at $37^{\circ} \mathrm{C}$ during 20 min with increasing concentrations of DNA (both circular and linear). The graph represents the released $\mathrm{Pi}$ in each condition. Mean \pm SEM from 3 independent experiments is shown. (C) rPpx1 activity on polyP in the presence of increasing amount of RNA. Same experiment as in B, but with increasing concentrations of RNA. The graph represents the released $\mathrm{Pi}$ in each condition. Mean \pm SEM from 3 independent experiments is shown. (D) Kinetics of rPpx1 polyP digestion in the presence of DNA and RNA. rPpx1 (1 ng) was incubated with $250 \mathrm{ng}$ of yeast polyP previously treated or not with a DNAse/ RNAse solution in $20 \mathrm{mM}$ Tris- $\mathrm{HCl} \mathrm{pH} 7.50$ containing $5 \mathrm{mM}$ magnesium acetate and $100 \mathrm{mM}$ ammonium acetate at $37^{\circ} \mathrm{C}$. Samples were taken at the indicated times and the released Pi was quantified. Mean \pm SEM from 3 independent experiments is shown. 
spermidine [20], act as inhibitors of Ppx1 activity, we considered this behavior a symptom of the presence of inhibitory molecules. Ethanol precipitation is extensively used to concentrate nucleic acids, such as DNA and RNA, which are negatively charged. Given that the polyP samples used in this assay were not treated with RNAse or DNAse, and to test the possible interference of nucleic acids in the efficiency of polyP degradation, we incubated polyP with 10 ng $(0.22 \mathrm{pmol})$ of $\mathrm{rPpx} 1$ in the presence of increasing amounts of linear or circular DNA. As showed in Figure 4B, linear DNA had a very strong inhibitory capacity, with total loss of enzymatic activity at an enzyme/DNA ratio of $\sim 20$. In contrast, circular DNA was less harmful to the process. Incubation with RNA resulted in some inhibition of the enzyme, although higher amounts of ribonucleic acid were needed. As documented in Figure 4D, treatment of the ethanol precipitated material extracted from yeast with a mixture of DNAse and RNAse not only accelerates the rate of the degradation reaction but also leads to a higher value for the amount of PolyP determined. These results would suggest a functional interaction between nucleic acids (mostly linear DNA) and Ppx1. Remarkably, poly(A) polymerase, an RNA-modifying enzyme, has been found to be inhibited by polyP [32]. Therefore, it must be concluded that accompanying nucleic acids can significantly interfere with the determination of polyP and that an excess of rPpx1 is recommend if it is likely the presence of nucleic acids in the assay.

\section{rPpx1 degradation followed by free phosphate determi- nation offers a better linear range than DAPI quantifica- tion}

An alternative to the enzymatic degradation of polyP followed by quantification of the released phosphate is the electrophoretic resolution of polyP chains and subsequent staining of the polymers with DAPI. To compare the linearity of both methods we quantified a range of polyP from 0.5 to $8 \mu \mathrm{g}$ by both enzymatic degradation and free Pi determination and DAPI staining of electrophoretically resolved polyP samples. As shown in Figure S2A the enzymatic method was linear within the entire tested range, whereas DAPI staining, due to saturation of the signal, was linear only for amounts of polyP up to $2 \mu \mathrm{g}$.

\section{Experimental comparison of reported methods for polyP determination}

Our precedent results indicate that the different steps in the determination of polyP from yeast cells can be a source of variation and could be at the origin of the large dispersions of values found in the literature (see Figure $1 \mathrm{~A}$ ). To directly test this possibility were carried out in our laboratory, for the same amount of cells, the determination of polyP using the procedures described by Neef and Kladde [33], Lichko and coworkers [23] and Hürliman et al. [25], in comparison with the one recently employed by our group [26]. All these methods have in common the enzymatic hydrolysis of polyP with exopolyphosphatase and chemical determination of the phosphate released, but differs in the upstream methodology.

As it can be seen in Figure $5 \mathrm{~A}$, the procedure described in Bru and coworkers, based in neutral phenol/chloroform extraction and ethanol precipitation after DNAse and RNAse treatment yielded an intracellular polyP concentration (expressed as $\mathrm{Pi}$ ) of nearly $95 \mathrm{mM}$. This value is used here as reference. In contrast, the method described by Hürliman and coworkers gave the lower yield, likely because the extraction in this method is carried out by sulfuric acid treatment, which has a detrimental impact in the recovery of polyP (see Figure $2 \mathrm{C}$ ), and because this step is followed by a Qiagen PCR column purification step, which is a second factor leading to polyP loss. Therefore, the accumulation of two detrimental steps in the entire process likely justifies the very low recovery observed for this method compared with the previous one (almost 20-fold lower). The method described by Neef and Kladde uses acid phenol and glass beads for extraction of polyP, which according to our results does not affect polyP recovery. However, these authors do not degrade nucleic acids with DNAses or RNAses prior enzymatic polyP degradation. Given the significant effect of these biomolecules on Ppx1 activity and polyP recovery (Figure 4), omission of this step could explain the somewhat lower recovery (about 30\%) obtained with this procedure compared with that described in Bru et al. [26]. Finally, the method described by Lichko and coworkers is based in the extraction of polyP with perchloric acid, which also has a detrimental effect in polyP recovery (see Figure $2 \mathrm{C}$ ). This might explain a polyP recovery of about one third compared with the reference value.

It is important to note that the procedure utilized for polyP determination can substantially affect the conclusions extracted from a given experiment. For instance, we have observed that the marked size-specificity of the chromatography column method used in the purification step can introduce a substantial bias when comparing different physiological conditions. As an example, we recently characterized the changes in cellular polyP in yeast cells exposed to sudden alkalization of the medium by using a column chromatography purification step [34]. Our results indicated a very rapid decrease, in a matter of few minutes, up to $15 \%$ of the initial polyP values. We were puzzled by such dramatic change, which was much faster than that obtained by depletion of $\mathrm{Pi}$ in the medium, and considered the possibility that it might be influenced by the determination procedure. Therefore, we repeated the experiment under identical conditions (using the neutral phenol extraction procedure) except that in one sample polyP was purified by affinity column and in the other the ethanol precipitation procedure was followed. As it can be observed in Figure S3, in untreated cells, utilization of the column step yields about $50 \%$ of the value obtained by the ethanol precipitation method. More importantly, according to the former method, alkalization of the medium leads to virtually complete depletion of polyP in about $2 \mathrm{~min}$, whereas the later procedure yields a decrease of only $25 \%$ of the original value. Time-course electrophoretic analysis of the sam- 
ples provides an explanation for such disparate results: high $\mathrm{pH}$ stress provokes rapid depletion of the largest polyP chains (the ones retained by the column). This result is not devoid of interest, as it might indicate that extracellular alkalization triggers the rapid activation of cellular endopolyphosphatases.

In conclusion, it is likely that most protocols described so far incur in one or more steps that negatively affect the yield of quantitated polyP and are at the basis of the dispersion of results obtained in many laboratories. Because there can be other (sometimes unavoidable) sources for variation in polyP content in yeast cells, such as the genetic background or the nature of the culture media, it is important to standardize as much as possible those factors that can be chosen at will. In this work we propose a protocol for total polyP extraction that integrates steps extracted from the literature with others shaped on the basis of the evidence presented here. This protocol is summa- rized in Figure 5B. Finally, our preliminary results (not shown) suggest that the protocol for polyP extraction and purification presented here can also be used for quantification of polyP from mammalian sources.

\section{MATERIALS AND METHODS \\ Yeast strains and growing conditions}

Saccharomyces cerevisiae BY4741 yeast strain [35] was used in all the experiments. Yeast cells were grown in $5 \mathrm{ml}$ of YPD medium (1\% Yeast extract, 2\% Peptone, 2\% Dextrose) overnight at $30^{\circ} \mathrm{C}$, diluted to $\mathrm{OD}$ (wavelength 660 $\mathrm{nm})=0.4 \mathrm{in} 10 \mathrm{ml}$ of fresh YPD and let them grow to OD = 1.5. The cells were harvested by centrifugation and instantly frozen by immersion in dry ice. In the alkaline stress experiments, cells were grown and harvested as in [36]. In all cases, pellets for polyP extraction were stored at $-80^{\circ} \mathrm{C}$.

B

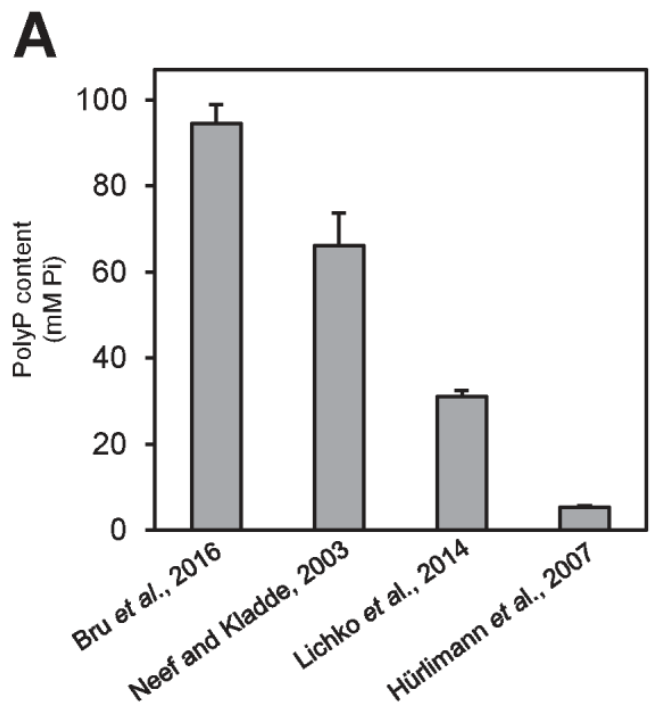

Resuspend the pellet with $400 \mu \mathrm{l}$ of $\mathrm{AE}$ buffer

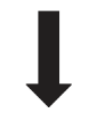

Add $300 \mu$ l of phenol $\mathrm{pH} 8.0$ (Figure 2)

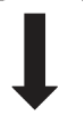

Heat at $65^{\circ} \mathrm{C}$

(Figure 4)

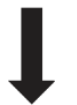

Add $300 \mu \mathrm{l}$ of chloroform and spin at $14,000 \mathrm{rpm} 2 \mathrm{~min}$

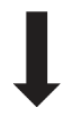

Transfer the supernatant to $350 \mu \mathrm{l}$ of chloroform and spin at $14,000 \mathrm{rpm} 2 \mathrm{~min}$

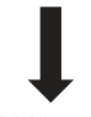

DNAse/RNAse treatment (Figure 4)

FIGURE 5: Comparison of different polyP extraction and purification methods. (A) Amount of polyP corresponding to $10^{7}$ logarithmically growing yeast cells extracted and purified with the following methods: neutral-phenol/chloroform and ethanol precipitation [26], acid-phenol/chloroform and ethanol precipitation [33], perchloric acid [23], and sulfuric acid and affinity columns [25]. Mean \pm SEM from 3 independent experiments is shown. (B) Scheme of the polyP extraction and purification protocol using neutral phenol and ethanol purification. In brackets appears the figure supporting this particular step. For details and tips see Materials and Methods.

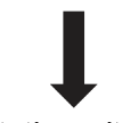

Precipitation with ethanol (Figure 3)

Quantification

(Figure S1) 
PolyP extraction and purification methods

Method 1: Neutral phenol/chloroform and ethanol precipitation

$1-2 * 10^{7}$ exponentially growing cells were collected, the pellet was resuspended with $400 \mu \mathrm{l}$ of AE buffer $(50 \mathrm{mM}$

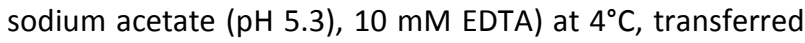
to a screw cap tube containing $300 \mu \mathrm{l}$ phenol and $40 \mu \mathrm{l}$ $10 \%$ SDS, mixed by inversion 4 times, vortexed $5 \mathrm{sec}$ to homogenize, incubated at $65^{\circ} \mathrm{C}$ for $5 \mathrm{~min}$ and chilled for 1 min on ice. Three-hundred $\mu$ of chloroform were added, mixed by inversion 4 times, vortexed $5 \mathrm{sec}$ to homogenize and centrifuged at room temperature for $2 \mathrm{~min}$ at 13,000 g. The top aqueous phase (around $450 \mu \mathrm{l}$ ) containing the polyP was transferred to a prepared $1.5 \mathrm{ml}$ screw cap tube containing $350 \mu \mathrm{l}$ chloroform (it is important not to carry over any phenol during pipetting by avoid touching the bottom phase or the white protein containing interphase), mixed by inversion 4 times, vortexed $5 \mathrm{sec}$ to homogenize, centrifuged at room temperature for $2 \mathrm{~min}$ at 13,000 g and the aqueous phase was transferred to a new $1.5 \mathrm{ml}$ microcentrifuge tube (it is important not to carry over any phenol). $2 \mu$ of RNAse A $10 \mathrm{mg} / \mathrm{ml}$ (Sigma R6513) and $2 \mu \mathrm{l}$ of DNAse I $10 \mathrm{mg} / \mathrm{ml}$ (Applichem, A3778.0100) were added, incubated $1 \mathrm{~h}$ at $37^{\circ} \mathrm{C}$, transferred to a pre-cold at $-20^{\circ} \mathrm{C} 1.5$ $\mathrm{ml}$ microcentrifuge tube containing $1 \mathrm{ml}$ of absolute ethanol and $40 \mu \mathrm{l}$ of $3 \mathrm{M}$ sodium acetate ( $\mathrm{pH} 5.3$ ), leaved $3 \mathrm{~h}$ at $-20^{\circ} \mathrm{C}$ to precipitate polyP and centrifuged for $20 \mathrm{~min}$ at $13,000 \mathrm{~g}$ at $4^{\circ} \mathrm{C}$. The supernatant was discarded by decantation, $500 \mu \mathrm{l}$ of $70 \%$ ethanol were added, centrifuged for $5 \mathrm{~min}$ at $13,000 \mathrm{~g}$ at $4^{\circ} \mathrm{C}$, the supernatant was discarded by decantation, centrifuged $1 \mathrm{~min}$ at $13,000 \mathrm{~g}$ and the last traces of ethanol were removed by pipetting. The tube was left open to dry the small translucent-white polyP pellet at room temperature for $5 \mathrm{~min}$ or until the pellet is completely dry. Finally, the polyP was resuspended in $50 \mu$ of Milli$\mathrm{Q}$ water. The polyP sample can be directly measured or stored at $-20^{\circ} \mathrm{C}$.

Method 2: acid phenol/chloroform and ethanol precipitation

PolyP extraction and purification was performed as described in [33]. Briefly, $10^{7}$ logarithmically growing yeast cells were centrifuged at 9,000 g for $1 \mathrm{~min}$. Pellets were resuspended in $350 \mu \mathrm{l}$ of LETS buffer $(0.1 \mathrm{M} \mathrm{LiCl}, 10 \mathrm{mM}$ EDTA, $10 \mathrm{mM}$ Tris $\mathrm{pH} 8.0,0.5 \%$ SDS) and $350 \mu$ of phenol $\mathrm{pH} 4.8$, lysed with the addition of $500 \mu \mathrm{l}$ glass beads and vortexed for $15 \mathrm{~min}$ at $4^{\circ} \mathrm{C}$. After centrifugation of the mixture at $18,000 \mathrm{~g}$ for $15 \mathrm{~min}$, the aqueous phase was transferred to a new Eppendorf tube and subjected to chloroform extraction as above. The supernatant was precipitated by adding $1 \mathrm{ml}$ of absolute ethanol followed by overnight incubation at $-20^{\circ} \mathrm{C}$. The pellet containing the polyP was resuspended in $50 \mu \mathrm{l}$ of $0.1 \%$ SDS, $1 \mathrm{mM}$ EDTA, $10 \mathrm{mM}$, Tris- $\mathrm{HCl}, \mathrm{pH} 7.4$.

Method 3: sulfuric acid extraction and affinity columns purification

PolyP extraction and purification was performed as described in [22]. Briefly, $10^{7}$ logarithmically growing yeast cells were centrifuged at 9,000 g for $1 \mathrm{~min}$. The pellets were incubated with $50 \mu \mathrm{l}$ of $1 \mathrm{M}$ sulfuric acid for $5 \mathrm{~min}$ at room temperature. The suspension was neutralized by adding $50 \mu \mathrm{l}$ of $2 \mathrm{M} \mathrm{NaOH}$ and cell debris removed by centrifugation. Finally, polyP was purified using MachereyNagel PCR affinity purification columns, and eluted in $50 \mu \mathrm{l}$ of MilliQ water.

\section{Method 4: perchloric acid extraction and purification}

PolyP extraction and purification was performed as described in [23]. Briefly, $10^{7}$ logarithmically growing yeast cells were centrifuged at 9,000 g for $1 \mathrm{~min}$. The pellet was resuspended in $250 \mu \mathrm{l}$ of $1 \mathrm{M}$ perchloric acid, lysed by adding $500 \mu \mathrm{l}$ of glass beads, vortex for $5 \mathrm{~min}$ at $4^{\circ} \mathrm{C}$, and centrifuged at $18,000 \mathrm{~g}$ for $5 \mathrm{~min}$ at $4^{\circ} \mathrm{C}$. The suspension was neutralized by adding $150 \mu \mathrm{l}$ of KCE solution $\left(1 \mathrm{M} \mathrm{K}_{2} \mathrm{CO}_{3}, 5\right.$ mM EDTA), and cooled down in ice for $2 \mathrm{~h}$. Cells debris was removed by centrifugation at $18,000 \mathrm{~g}$. Finally, the supernatant was transferred to a new Eppendorf tube to be quantified.

\section{polyP quantification}

PolyP amount was determined as a measure of the inorganic phosphate produced by the complete digestion of the polyP by treatment with recombinant $\mathrm{rPpx} 1$ polyphosphatase protein [37]; briefly, E. coli BL21 cells transformed with pTrCPPX1 plasmid (kindly provided by A. Kornberg) containing yeast $P P X 1$ were grown over night at $37^{\circ} \mathrm{C}$ in 50 $\mathrm{ml}$ of LB (Luria Bertani medium), and the culture used as inoculum to a $500 \mathrm{ml}$ culture in the same LB medium containing $0.5 \mathrm{mM}$ IPTG as inducer. Growth was continued for $6 \mathrm{~h}$ at $25^{\circ} \mathrm{C}, \mathrm{E}$. coli cells were harvested by centrifugation, lysed and the recombinant proteins purified using $\mathrm{Ni}$ nitrilotriacetic acid agarose (Qiagen, ID:30210). The purified polyP samples to be measured were diluted in $100 \mu \mathrm{l}$ of a solution containing $20 \mathrm{mM}$ Tris- $\mathrm{HCl}(\mathrm{pH} 7.5), 100 \mathrm{mM}$ $\mathrm{NH}_{4}$ acetate, $5 \mathrm{mM} \mathrm{Mg}$ acetate, and $10 \mathrm{ng}$ (measured by Bradford method) of $\mathrm{rPpx} 1$ for $1 \mathrm{~h}$ at $37^{\circ} \mathrm{C}$. To quantify the released $\mathrm{Pi}, 86 \mu \mathrm{l}$ of $28 \mathrm{mM}$ ammonium heptamolybdate in $2.1 \mathrm{M}$ sulfuric acid and $64 \mu \mathrm{l}$ of $0.41 \mathrm{mM}$ malachite green were added to the digested solution [38]. The $\mathrm{OD}_{595}$ was measured in a Synergy HT Elisa Reader and interpolation in a standard curve was used for obtaining absolute $\mathrm{Pi}$ amount values.

\section{polyP detection by PAGE}

Purified polyP was resolved electrophoretically using a $20 \%$ polyacrylamide gel (acrylamide 10:1 bisacrylamide) containing $7 \mathrm{M}$ urea in TBE buffer $\mathrm{pH} 8.3$, at $250 \mathrm{~V} / \mathrm{h}$ for $5 \mathrm{~h}$ at $4^{\circ} \mathrm{C}$. The dimensions of the gel were $200 \mathrm{~mm}$ height, 200 $\mathrm{mm}$ wide and $1.5 \mathrm{~mm}$ thick. The gel was stained by soaking it in the staining solution ( $25 \%$ methanol, $5 \%$ glycerol, 2 $\mu \mathrm{g} / \mathrm{ml}$ DAPI, $50 \mathrm{mM}$ Tris $\mathrm{pH} 10.5$ ) for $30 \mathrm{~min}$, and destained by soaking it in destaining solution (same as the staining solution but without DAPI) for $1 \mathrm{~h}$. Finally, to visualize the polyP the gel was exposed to $254 \mathrm{~nm}$ UV light in Syngene G-BOX trans-illuminator. 


\section{Assessment of rPpx1 optimal activity}

The optimal temperature, and $\mathrm{pH}$ value for $\mathrm{rPpx} 1$ activity was determined by incubating $1 \mathrm{ng}$ of $\mathrm{rPpx} 1$ and $5 \mu \mathrm{g}$ of commercial polyP (Shiba Regenetiss, Inc.) at several temperatures and $\mathrm{pH}$ values respectively in $20 \mathrm{mM}$ Tris $-\mathrm{HCl} \mathrm{pH}$ 7.50 (when temperature was varied) containing $5 \mathrm{mM}$ magnesium acetate and $100 \mathrm{mM}$ ammonium acetate. In the case of the $\mathrm{pH}$ optimal value assessment the incubation temperature was $37^{\circ} \mathrm{C}$.

The influence of DNA or RNA presence in the activity of rPpx1 was assayed using $10 \mathrm{ng}$ of rPpx1 and $100 \mathrm{ng}$ of commercial polyP in the same buffer as above but adding increasing amounts of DNA (circular pUC19 vector or a lineal PCR fragment of $1.7 \mathrm{~Kb}$ ) or RNA (yeast tRNA from Sigma).

$\mathrm{rPpx} 1$ activity is expressed as $\mathrm{ng}$ of Pi released/ $\mathrm{min} / \mathrm{ng}$ of enzyme.

\section{ACKNOWLEDGEMENTS}

We want to thanks A. Kornberg for the plasmid pTrcPPX1 and M. Pérez for invaluable technical assistance. This work has been funded by the Spanish Ministerio de Economía y Competitividad MINECO grants ref: BFU 2013-44189-P to JC ; BFU2011-30197-C3-01 and BFU2014-54591-C2-1-P to JA. SB was the recipient of a grant from the UIC.

\section{REFERENCES}

1. Rao NN, Gomez-Garcia MR, and Kornberg A (2009). Inorganic polyphosphate: essential for growth and survival. Annu.Rev.Biochem. 78: 605-647.

2. Azevedo C, Livermore T, and Saiardi A (2015). Protein polyphosphorylation of lysine residues by inorganic polyphosphate. Mol.Cell. 58(1): 71-82

3. Angelova PR, Baev AY, Berezhnov AV, and Abramov AY (2016). Role of inorganic polyphosphate in mammalian cells: from signal transduction and mitochondrial metabolism to cell death. Biochem.Soc.Trans. 44(1): 40-45.

4. Kulakovskaya T, Vagabov V, and and Kulaev I (2012). Inorganic Polyphosphate in Industry, Agriculture and Medicine: Modern State and Outlook. Process Biochemistry. 47(1): 1-10.

5. Beauvoit B, Rigoulet $M$ and Guerin $P$, and Canioni $P$ (1989). Polyphosphates as a source of high energy phosphates in yeast mitochondria: a 31P NMR study. FEBS Lett. 252(1(2)): 17-21.

6. Castro CD, Meehan AJ, Koretsky AP, and Domach MM (1995). In situ 31P nuclear magnetic resonance for observation of polyphosphate and catabolite responses of chemostat-cultivated Saccharomyces cerevisiae after alkalinization. Appl.Environ.Microbiol. 61(12): 44484453.

7. Diaz J, Ingall E, Benitez-Nelson C, Paterson D, de Jonge MD, McNulty $\mathrm{I}$, and Brandes JA (2008). Marine polyphosphate: a key player in geologic phosphorus sequestration. Science. 320(5876): 652-655.

8. Mullan A, Quinn JP, and McGrath JW (2002). A nonradioactive method for the assay of polyphosphate kinase activity and its application in the study of polyphosphate metabolism in Burkholderia cepacia. Anal.Biochem. 308(2): 294-299.

\section{SUPPLEMENTAL MATERIAL}

All supplemental data for this article are available online at www.microbialcell.com.

\section{CONFLICT OF INTEREST}

The authors declare no conflict of interest.

\section{COPYRIGHT}

(C) 2016 Bru et al. This is an open-access article released under the terms of the Creative Commons Attribution (CC BY) license, which allows the unrestricted use, distribution, and reproduction in any medium, provided the original author and source are acknowledged.

Please cite this article as: Samuel Bru, Javier Jiménez, David Canadell, Joaquín Ariño, Josep Clotet (2016). Improvement of biochemical methods of polyP quantification. Microbial Cell 4(1): 6-15. doi: 10.15698/mic2017.01.551

9. Tijssen JP, Beekes HW, and Van Steveninck J (1982). Localization of polyphosphates in Saccharomyces fragilis, as revealed by 4',6diamidino-2-phenylindole fluorescence. Biochim.Biophys.Acta. 721(4): 394-398.

10. Aschar-Sobbi R, Abramov AY, Diao C, Kargacin ME, Kargacin GJ, French RJ and Pavlov E (2008). High sensitivity, quantitative measurements of polyphosphate using a new DAPI-based approach. J.Fluoresc. 18(5): 859-866.

11. Martin P, and Van Mooy BA (2013). Fluorometric quantification of polyphosphate in environmental plankton samples: extraction protocols, matrix effects, and nucleic acid interference. Appl.Environ.Microbiol. 79(1): 273-281.

12. Omelon S, Georgiou J, and Habraken W (2016). A cautionary (spectral) tail: red-shifted fluorescence by DAPI-DAPI interactions. Biochem.Soc.Trans. 44(1): 46-49.

13. Kolozsvari B, Firth S, and Saiardi A (2015). Raman spectroscopy detection of phytic acid in plant seeds reveals the absence of inorganic polyphosphate. Mol.Plant. 8(5): 826-828.

14. Kolozsvari B, Parisi F, and Saiardi A (2014). Inositol phosphates induce DAPI fluorescence shift. Biochem.J. 460(3): 377-385.

15. Omelon S, Georgiou J, Variola F, and Dean MN (2014). Colocation and role of polyphosphates and alkaline phosphatase in apatite biomineralization of elasmobranch tesserae. Acta Biomater. 10(9): 38993910.

16. Kumble KD, and Kornberg A (1995). Inorganic polyphosphate in mammalian cells and tissues. J.Biol.Chem. 270(11): 5818-5822. 
17. Ault-Riche D, Fraley CD, Tzeng CM, and Kornberg A (1998). Novel assay reveals multiple pathways regulating stress-induced accumulations of inorganic polyphosphate in Escherichia coli. J.Bacteriol. 180(7): 1841-1847.

18. Motomura K, Hirota R, Ohnaka N, Okada M, Ikeda T, Morohoshi T, Ohtake $H$, and Kuroda A (2011). Overproduction of YjbB reduces the level of polyphosphate in Escherichia coli: a hypothetical role of YjbB in phosphate export and polyphosphate accumulation. FEMS Microbiol.Lett. 320(1): 25-32.

19. Ruiz FA, Rodrigues CO, and Docampo R (2001). Rapid changes in polyphosphate content within acidocalcisomes in response to cell growth, differentiation, and environmental stress in Trypanosoma cruzi. J.Biol.Chem. 276(28): 26114-26121.

20. Wurst $\mathrm{H}$, and Kornberg A (1994). A soluble exopolyphosphatase of Saccharomyces cerevisiae. Purification and characterization. J.Biol.Chem. 269(15): 10996-11001.

21. Seidlmayer LK, Gomez-Garcia MR, Blatter LA, Pavlov E, and Dedkova EN (2012). Inorganic polyphosphate is a potent activator of the mitochondrial permeability transition pore in cardiac myocytes. J.Gen.Physiol. 139(5): 321-331.

22. Werner TP, Amrhein N, and Freimoser FM (2005). Novel method for the quantification of inorganic polyphosphate (iPoP) in Saccharomyces cerevisiae shows dependence of iPoP content on the growth phase. Arch.Microbiol. 184(2): 129-136.

23. Lichko LP, Eldarov MA, Dumina MV, and Kulakovskaya TV (2014). PPX1 gene overexpression has no influence on polyphosphates in Saccharomyces cerevisiae. Biochemistry (Mosc). 79(11): 1211-1215.

24. Kornberg A (1999). Inorganic polyphosphate: a molecule of many functions. Prog.Mol.Subcell.Biol. 23: 1-18.

25. Hurlimann HC, Stadler-Waibel M, Werner TP, and Freimoser FM (2007). Pho91 is a vacuolar phosphate transporter that regulates phosphate and polyphosphate metabolism in Saccharomyces cerevisiae. Mol.Biol.Cell. 18(11): 4438-4445.

26. Bru S, Martinez JM, Hernandez-Ortega S, Quandt E, TorresTorronteras J, Marti RR, Canadell D, Arino J, Sharma S, Jimenez J, and Clotet J (2016). Polyphosphate is involved in cell cycle progression and genomic stability in Saccharomyces cerevisiae. Mol. Microbiol. 101(3): 367-80.

27. Harold FM (1966). Inorganic polyphosphates in biology: structure, metabolism, and function. Bacteriol.Rev. 30(4): 772-794.
28. Lichko L, Kulakovskaya T, Pestov N, and Kulaev I (2006). Inorganic polyphosphates and exopolyphosphatases in cell compartments of the yeast Saccharomyces cerevisiae under inactivation of PPX1 and PPN1 genes. Biosci.Rep. 26(1): 45-54.

29. Vagabov VM, Trilisenko LV, Kulakovskaya TV, and Kulaev IS (2008). Effect of a carbon source on polyphosphate accumulation in Saccharomyces cerevisiae. FEMS Yeast Res. 8(6): 877-882.

30. Kulaev IS, Andreeva NA, Lichko LP, and Kulakovskaya TV (1997). Comparison of exopolyphosphatases of different yeast cell compartments. Microbiol.Res. 152(3): 221-226.

31. Lichko LP, Kulakovskaya TV, and Kulaev IS (2003). Nuclear exopolyphosphatase of Saccharomyces cerevisiae is not encoded by the PPX1 gene encoding the major yeast exopolyphosphatase. FEMS Yeast Res. 3(1): 113-117.

32. Holbein S, Freimoser FM, Werner TP, Wengi A, and Dichtl B (2008). Cordycepin-hypersensitive growth links elevated polyphosphate levels to inhibition of poly(A) polymerase in Saccharomyces cerevisiae. Nucleic Acids Res. 36(2): 353-363.

33. Neef DW, and Kladde MP (2003). Polyphosphate loss promotes SNF/SWI- and Gcn5-dependent mitotic induction of PHO5. Mol.Cell.Biol. 23(11): 3788-3797.

34. Serra-Cardona A, Canadell D, and Ariño J (2015). Coordinate responses to alkaline $\mathrm{pH}$ stress in budding yeast. Microbial Cell. 2(6): 182-196.

35. Brachmann CB, Davies A, Cost GJ, Caputo E, Li J, Hieter P, and Boeke JD (1998). Designer deletion strains derived from Saccharomyces cerevisiae S288C: a useful set of strains and plasmids for PCRmediated gene disruption and other applications. Yeast. 14(2): 115132.

36. Canadell D, Gonzalez A, Casado C, and Arino J (2015). Functional interactions between potassium and phosphate homeostasis in Saccharomyces cerevisiae. Mol.Microbiol. 95(3): 555-572.

37. Wurst H, Shiba T, and Kornberg A (1995). The gene for a major exopolyphosphatase of Saccharomyces cerevisiae. J.Bacteriol. 177(4): 898-906.

38. Cogan EB, Birrell GB, and Griffith OH (1999). A robotics-based automated assay for inorganic and organic phosphates. Anal.Biochem. 271(1): 29-35. 